\title{
Showcasing the 2021 TMS Scholars
}
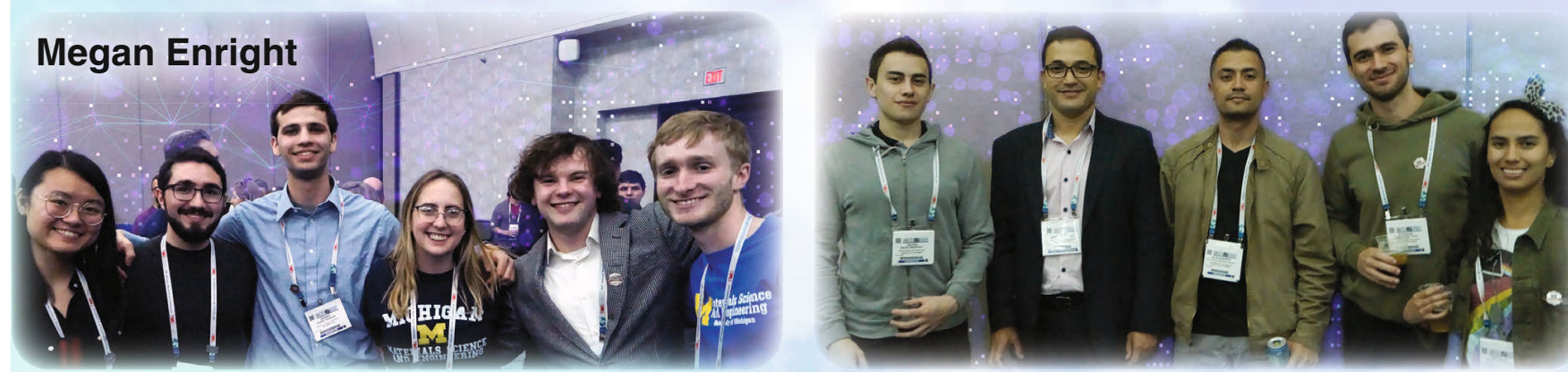

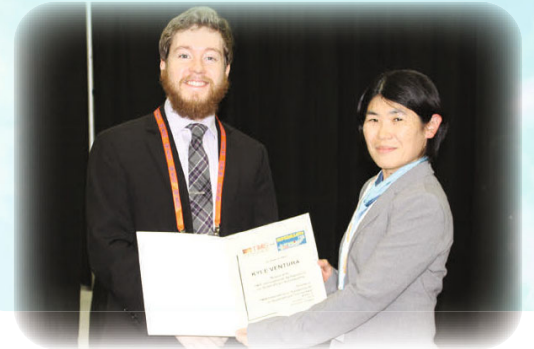

This Class of 2021 TMS Scholars represent the bright future of the minerals, metals, and materials professions. From their testimonials, the TMS community has provided them with opportunities to grow and learn, to meet new people in their fields, and much-appreciated financial assistance which has allowed them to continue their studies and work in these fields.

In addition to the assistance with the cost of education, many of the scholarships awarded include travel grants to aid these students in attending highly regarded professional meetings. This allows

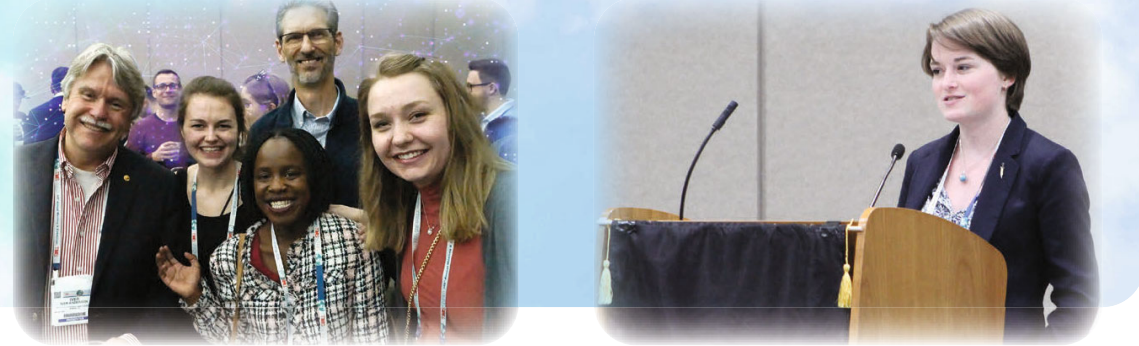

these students to begin connecting with professionals in their fields, expand their technical knowledge, and uild their professional profile.

Several of these scholarships will be awarded during the TMS 2021 Annual Meeting \& Exhibition (TMS2021) technical division functions. Be sure to support this promising group of scholars and congratulate them on all their achievements. Furthermore, various other awards and scholarships will be conferred at the TMSAIME Awards Ceremony during TMS2021. Learn more about TMS2021 awards events at www.tms.org/TMS2021.

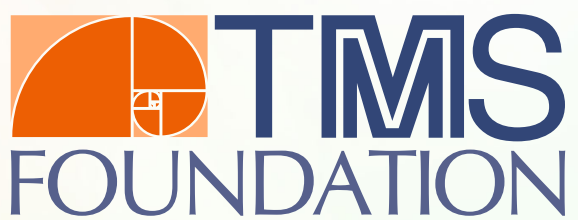

The scholarships featured in this article not only remove boundaries to education, but also support students in pursuing a deeper involvement in the greater materials community that can help open doors and build careers. And right now, students are facing unprecedented challenges to their career paths, making the assistance and assurance provided by these scholarships more important than ever.

All of the awards are made possible by the

\section{Your Gift Can Support Students} Like These

TMS Foundation and its generous supporters. You can ensure that the good work of the Foundation continues by making a donation today. Visit www.TMSFoundation.org/Contribute to make a one-time donation or set up a monthly gift. You can also send a check, payable to the TMS Foundation, to 5700 Corporate Drive Suite 750 , Pittsburgh, PA 15237. For more information or to discuss donation options, contact TMS Foundation staff at TMSFoundation@tms.org. 


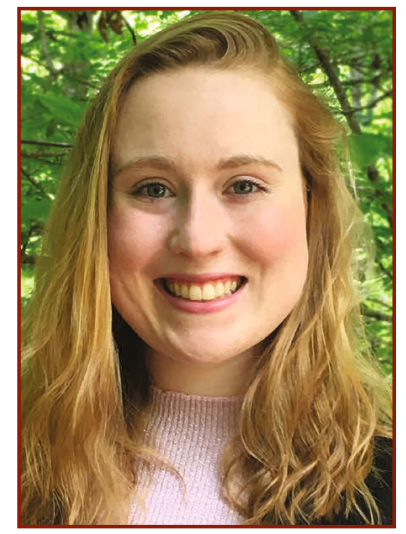

Lily Turaski

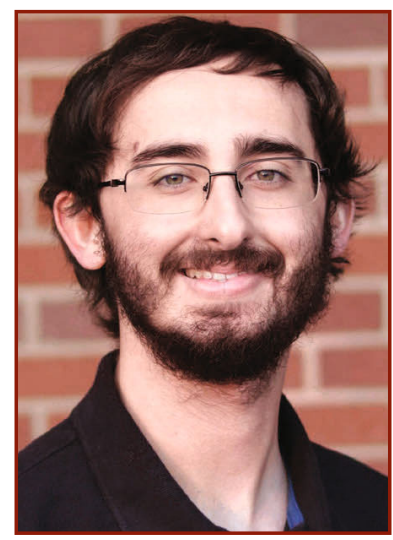

Zachary Wolff

\section{TMS DIVISION AWARDS}

TMS division scholarships recipients will also receive a dollar-for-dollar scholarship match through the Battelle Matching Scholarship Program. This is made possible through the generous support of Battelle and its retired chief executive officer, Jeffrey Wadsworth. Additionally, students who receive a Battelle Matching Scholarship will be eligible for a Battelle Materials Graduate Student Award when they matriculate to a graduate school to continue studies in a materials-related field.

\section{FUNCTIONAL MATERIALS DIVISION (FMD) GILBERT CHIN SCHOLARSHIP}

Awarded through the FMD and the TMS

Foundation to sophomore or junior

undergraduate students studying subjects related to synthesis and processing, structure, properties, and performance of electronic, photonic, magnetic, and superconducting materials, as well as materials used in packaging and interconnecting such materials in device structures.

\section{Lily Turaski}

Georgia Institute of Technology (Georgia Tech)

"TMS and Material Advantage have made an immense impact on my education and career path. I attended my first TMS annual meeting as a freshman. I loved learning about innovations and discoveries at the forefront of materials research and meeting fellow materials science and engineering students, professors, and industry professionals. That first experience cemented my love of materials science and ensured I would be a regular conference-goer," Turaski said. "Since then, I have had the opportunity to present research posters, participate in the Undergraduate Speaking Contest, and enter the Material Bowl Competition. I have also been involved in the Material Advantage

"I am so thankful that TMS, Battelle, and the Functional Materials Division are investing in students like me." -Lily Turaski

chapter at Georgia Tech, where I am currently serving as vice president. I enjoy getting other students involved in Material Advantage and showing them the benefits of a professional society. I plan to attend graduate school and obtain a Ph.D. in materials science with a focus in electronic materials. I am so thankful that TMS, Battelle, and the Functional Materials Division are investing in students like me."

\section{LIGHT METALS DIVISION (LMD) SCHOLARSHIP}

Awarded through the LMD and the TMS Foundation to outstanding sophomore or junior undergraduate students majoring in metallurgical and/or materials science and engineering with an emphasis on both traditional and emerging light metals.

\section{Zachary Wolff}

\section{University of Nevada, Reno}

"The TMS Foundation and Material Advantage have been imperative components to my academic career. TMS has kept me up-to-date on new events and opportunities occurring in the materials science and engineering field; one of which is the TMS Annual Meeting \& Exhibition, where scientists and students alike are able to present their research and findings to the materials community. Material Advantage has provided a medium to communicate with our peers, allowing us to organize activities to explore various organizations and corporations," Wolff said. "After I graduate, I would like to continue my education by obtaining a master's degree, studying irradiated materials and radiation detection. Currently, I work for the Nevada National Security Site in hopes of attaining a full-time career as a materials engineer." 


\section{MATERIALS PROCESSING \& MANUFACTURING DIVISION (MPMD) SCHOLARSHIPS}

Awarded through the MPMD and the TMS Foundation to sophomore or junior undergraduate students majoring in metallurgical and/or materials science and engineering, with an emphasis on manufacturing, integrating process control technology into manufacturing, and basic and applied research into key materials technologies that impact manufacturing processes.

\section{Alexander Goldman \\ University of Nevada, Reno}

"It is the personal connections and friends that I make through Material Advantage that I enjoy the most. Through having technical discussions with my peers and discussing career opportunities with my mentors, I have gained great confidence in beginning my research and choosing my path. Attending the TMS 2020 Annual Meeting $\&$ Exhibition was the most enjoyable experience I have had as an engineer. I was given countless opportunities to learn and engage with people from all backgrounds, which helped me find new interests and start relationships with incredibly bright and talented members of TMS. I will always be grateful for the help and guidance I have received from the kind community surrounding materials science and engineering," Goldman stated. "I plan to research renewable energy in a materials science master's program after I graduate in the spring. After I complete my academic education, I hope to follow my dreams with a career in the aerospace sector. I have always loved anything that flies, and I cannot wait to contribute my exciting plans toward an even more exciting field!"

\section{STRUCTURAL MATERIALS DIVISION (SMD) \\ SCHOLARSHIPS}

Awarded through the SMD and the TMS

Foundation to sophomore or junior undergraduate students majoring in metallurgical and/or materials science and engineering with an emphasis on the science and engineering of load-bearing materials, including studies into the nature of a material's physical properties based upon its microstructure and operating environment.

\section{Jadzia Graves \\ University of Idaho}

"It is a great honor to be recognized by TMS with the Structural Materials Division Scholarship for the second year. Being part of Material Advantage and TMS has given me a great opportunity to learn and grow as an engineering student and an individual. Receiving this scholarship will help me achieve my academic goals by allowing me to focus on my classes rather than my financial situation. I am extremely thankful for the opportunities that have given me the experiences necessary to qualify for this scholarship and hope to continue to further my experience in structural materials."

\section{N. \\ MATERIAL"}

Everything Else Is Immateria/

\section{Explore Opportunities with Material Advantage}

Material Advantage gives students access to technical resources, grant money, networking opportunities, and scholarships such as those highlighted in this article. For a single membership fee, the Material Advantage student program allows undergraduate and postgraduate students to benefit from membership in four materials-related societies-The American Ceramic Society (ACerS), the Association for Iron \& Steel Technology (AIST), ASM International, and TMS.

Visit www.materialadvantage.org to explore all of the opportunities the program has to offer or join today.

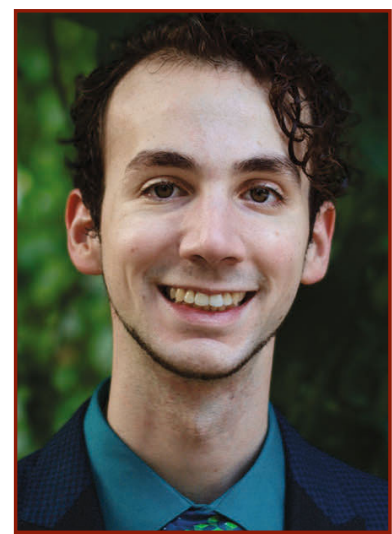

Alexander Goldman

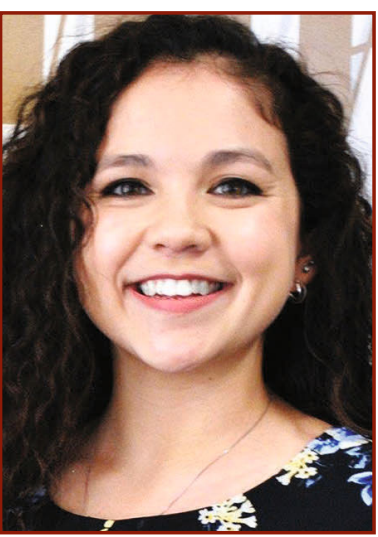

Jadzia Graves

“I will always

be grateful for

the help and

guidance I

have received

from the kind

community

surrounding

materials

science and

engineering."

-Alexander

Goldman 


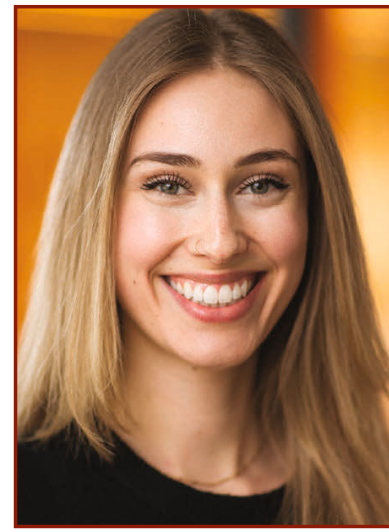

T.M. Kelsey Green

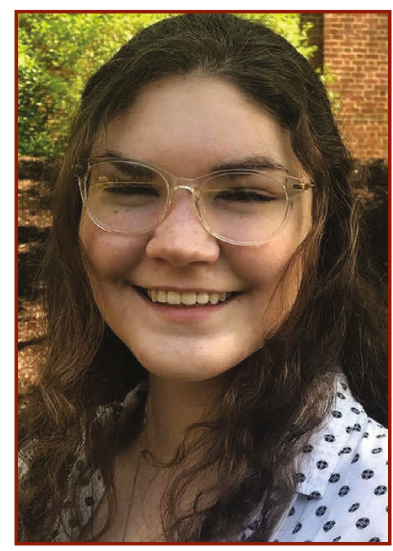

Justine Schulte

\section{SOGIETY AWARDS}

\section{TMS INTERNATIONAL SYMPOSIUM ON SUPERALLOYS SCHOLARSHIP}

This award is for undergraduate and graduate students majoring in metallurgical and/or materials science and engineering with an emphasis on all aspects of the high-temperature, highperformance materials used in the gas turbine industry and all other applications. Awards are presented in conjunction with the Materials Science and Technology Conference or the International Symposium on Superalloys.

\section{T.M. Kelsey Green}

\section{University of Michigan-Ann Arbor}

"I am greatly honored to receive the TMS International Symposium on Superalloys Scholarship. Receiving this scholarship underscores the importance and quality of my research on alloys for advanced nuclear applications and motivates me to continue my devotion to advancing the field. I am excited for the opportunity this scholarship provides, including the ability to continue my professional development via attendance and presentations at TMS conferences. After completing my Ph.D., I wish to continue developing my technical skills as a materials scientist at a national laboratory. Throughout my career, I also aim to influence and develop energy policy."

\section{Justine Schulte \\ University of Virginia}

"I am incredibly honored to be one of the recipients of the TMS International Symposium on Superalloys Scholarship and I would like to express my thanks to the selection committee for their recognition. After graduating from the University of Virginia, I plan to pursue a higher degree in a materials sciencerelated field," Schulte explained. "My Material Advantage membership has proved to be an invaluable tool during the process of applying to graduate programs, as it provides access to numerous materials science societies and opportunities to network with professionals in the field. This exposure to the different facets of the field has assisted me in exploring my interests and determining an area that truly speaks to me as a researcher. The resources generously provided by this scholarship will help support my undergraduate education, while yielding additional funds to pay for graduate school applications."

\section{Apply for a 2022 TMS Scholarship}

If you are a full-time undergraduate or graduate student interested in financial assistance, early career recognition, and important opportunities for advancement through technical exchanges at the TMS Annual Meeting \& Exhibition, consider applying for a 2022 TMS Scholarship.

Applicants must submit a completed TMS scholarship application, up to three recommendations, a personal statement, and a transcript with current GPA to Bryn Simpson, TMS Membership and Volunteerism Program Manager, at bsimpson@tms.org. The deadline to apply for a 2022 award is March 15, 2021.

Visit awards.tms.org to learn more about scholarship submission details and to access their application forms.



William Carpenter (right), South Dakota School of Mines \& Technology, receives the Extraction \& Processing Division Scholarship at the TMS 2020 Annual Meeting \& Exhibition (TMS2020). 